\title{
Synthesis, characterization and properties of novel thermally stable copoly(amide-imide)s containing dimethylsilane moieties
}

\author{
Majid Kolahdoozan, ${ }^{12^{*}}$ Monir S. Ghoreishi ${ }^{1}$ \\ ${ }^{1 *}$ Department of Chemistry, Islamic Azad University, Shahreza Branch, 311-86145, \\ Shahreza, Isfahan, Iran; e-mail: kolahdoozan@iaush.ac.ir. \\ ${ }^{2}$ Razi Chemistry Research Center, Islamic Azad University, Shahreza Branch, \\ Shahreza, Isfahan, Iran.
}

(Received: 06 May, 2010; published: 18 February, 2011)

\begin{abstract}
New type of poly(amide-imide)s were prepared based on novel diacid monomer containing softening siloxane groups. Bis( $p$-aminophenoxy) dimethyl silane (3) was prepared by the reaction of dimethyl dichlorosilane with $p$ aminophenol in toluene. $N, N^{\prime}$-Bis(4-trimellitimidophenoxy) dimethylsilane (5) as a novel aromatic dicarboxylic acid containing silicone moiety was synthesized by condensation of bis( $p$-aminophenoxy) dimethylsilane with trimelitic anhydride in acetic acid. The structure of diacid $\mathbf{5}$ was confirmed using various spectroscopy methods. The direct polycondensation technique was used for the polyamidation of monomer $\mathbf{5}$ with several aromatic diamines using pyridine / 2-methylpyrrolidone / triphenyl phosphite $/ \mathrm{CaCl}_{2}$ as condensing agent. The resulting novel poly(amideimide-siloxane)s were obtained in high yields and inherent viscosities. These polymers were characterized using FT-IR, ${ }^{1} \mathrm{H}-\mathrm{NMR}$, thermogravimetric and elemental analysis techniques. The results show that silicone modified poly(amideimide)s show high solubility and excellent thermal stability.

Key words: poly(amide-imide); silicone; polycondensation; inherent viscosity; thermally stable polymers
\end{abstract}

\section{Introduction}

Organic polymers are one of the most versatile groups of materials that combine light weight, cost-effectiveness, and processibility. Among the various heterocyclic polymers investigated for high-performance applications, aromatic polyimides are used widely in the semiconductor and electronic-packaging industries because of their outstanding thermal stability, good insulation properties with a low dielectric constant, good adhesion to common substrates, and superior chemical stability [1, 2]. Aromatic polyamides are hydrophilic polymers that can absorb water because of their amide linkages. Therefore, these polymers are good candidates for semipermeable membranes, particularly for the filtration of aqueous solutions and for water purification [3]. However, these polymers are generally intractable and lack the properties essential for successful fabrication into useful forms because of their high melting or glass-transition temperatures $\left(\mathrm{T}_{g}\right.$ 's) and their limited solubility in organic solvents [4].

Much effort has been made to create structurally modified aromatic polymers having better characterization in terms of both solubility and processability with retention of their high thermal stability. Introduction of flexible chains into the polyamide backbone $[5,6]$, the use of meta-oriented monomers $[7,8]$, synthesis of polymers with 
noncoplaner unit in the polymer chains [9], preparation of copolymers such as poly(ester amide)s [10], poly(amide-ester-imide)s [11,12] and cardo copolymers [13] resulted in a number of modified polyamides. A further strategy is based on the introduction of bulky side groups into the polymer chains [14-20]. A limitation for the preparation of polyarylate with pendant functional groups on the accurate sites is that most of wholly aromatic polymers are insoluble and infusible by virtue of their dense rigid structures [21].

Another way for improving solubility and lowering the $T_{\mathrm{g}}$ of aromatic polymers is the introduction of silane moieties in the main chain [22, 23]. Organosilicon chemistry plays an increasingly important role in organic synthesis. Since the silicon can serve as an important bridge between the organic and inorganic materials, recently, the silicon-containing polymers have received considerable attention [24]. In addition, these polymers are biocompatible and can be used in different applications such as controlled drug delivery systems $[25,26]$.

The solubility and melting processability of the polyoxadiazoles, polyesters, polyamides and polyimides containing silicone group in the main chain polymer were improved [27-30]. Meanwhile, the ionic characteristic of Si-C bond and the lower electronegativity of the silicon with respect to the carbon atom increased the thermal stability of the polymer. On the other hand, the silicon having aromatic neighbors is able to give $s-p$ conjugation, which is advantageous for the electron and hole transport along the polymer chain so that silicon-containing polymers show the potential applications in the field of optoelectronic materials [31].

In this article, $N, N^{\prime}$-bis(4-trimellitimidophenoxy) dimethylsilane as a novel diaicd monomer containing siloxane and imide linkage was prepared. Direct polyamidation of this diacid with different aromatic diamines were carried out using phosphorylation reaction. Softening siloxane group were incorporated within the main chain of resulting poly(amide-imide-siloxane)s (PAISs). Thereby, the polymers showed good solubility and thermal stability.

\section{Results and discussion}

\section{Monomer synthesis}

The diamine $\mathbf{3}$ was synthesized by the condensation reaction of $p$-aminophenol (1) and dichlorodimethylsilane (2) in dry toluene in the presence of triethylamine (Scheme 1). Chemical structure and purity of the compound $\mathbf{3}$ was proven by using TLC, using n-hexan:tetrahydrofurane $(60: 40)$ as eluent and FT-IR spectroscopy technique. In FT-IR spectrum of this diamine the peak at $3400 \mathrm{~cm}^{-1}$ shows amino groups and peaks at $1260,2950 \mathrm{~cm}^{-1}$ are attributed to $\mathrm{Si}_{-} \mathrm{CH}_{3}$ groups. In addition strong peaks at $1077 \mathrm{~cm}^{-1}$ and $933 \mathrm{~cm}^{-1}$ confirms Si-O and Si-O-Ph linkages, respectively.

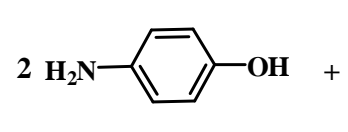

(1)<smiles>CC(C)(Cl)Cl</smiles>

(2)

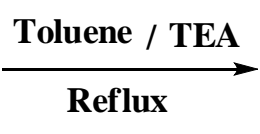

Reflux<smiles>CC(C)(Oc1ccc(N)cc1)Oc1ccc(N)cc1</smiles>

(3)

Scheme 1. Synthesis of bis-( $p$-aminophenoxy) dimethylsilane (3). 
The diamine 3 was reacted with trimellitic anhydride (4) in glacial acetic acid (Scheme 2) to yield novel diacid monomer $\mathbf{5}$ containing imide and siloxane groups. The structure and chemical purity of this novel compound was confirmed using TLC, elemental analysis, FT-IR (Figure 1), ${ }^{1} \mathrm{H}-\mathrm{NMR}$ (Figure 2) and ${ }^{13} \mathrm{C}-\mathrm{NMR}$ spectroscopy methods. TLC shows one spot for this diacid using n-hexan:tetrahydrofurane (50:50) as eluent. Elemental analysis shows good agreement between calculated and found value for carbon, hydrogen and nitrogen contents. In Figure 1 broad peak around $2600-3500 \mathrm{~cm}^{-1}$ show $\mathrm{OH}$ of carboxylic acid group, two peaks at 1705 and $1782 \mathrm{~cm}^{-1}$ are attributed to the symmetry and asymmetry stretching $\mathrm{C}=\mathrm{O}$ of imide groups. Two other peaks at 723 and $1390 \mathrm{~cm}^{-1}$ confirms imide heterocyclic ring. $\mathrm{Si}-\mathrm{CH}_{3}$ peaks appeared at $1211 \mathrm{~cm}^{-1}$. Other peaks at $1092 \mathrm{~cm}^{-1}$ and $932 \mathrm{~cm}^{-1}$ prove the existence of $\mathrm{Si}-\mathrm{O}$ and Si-O-Ph connections, respectively.

The ${ }^{1} \mathrm{H}$-NMR of this monomer (Figure 2) shows the characteristic absorption of $\mathrm{CH}_{3}$ at $0 \mathrm{ppm}$, aromatic hydrogen between 6.8-8.3 ppm and acidic hydrogen at $13.8 \mathrm{ppm}$. The ${ }^{13} \mathrm{C}$-NMR of diacid 5 (Figure 3) shows twelve different carbons from 116-167 ppm and one type of carbon near 0 ppm.<smiles>CC(=O)OCc1ccc(O[Si](C)(C)Oc2ccc(N)cc2)cc1</smiles><smiles>[131IH]</smiles>

(3)<smiles>CC(C)(Oc1ccc(N2C(=O)c3ccc(C(=O)O)cc3C2=O)cc1)Oc1ccc(N2C(=O)c3ccc(C(=O)O)cc3C2=O)cc1</smiles>

(5)

Scheme 2. Synthesis of $N, N^{\prime}$-bis-(4-trimellitimidophenoxy) dimethylsilane (5).

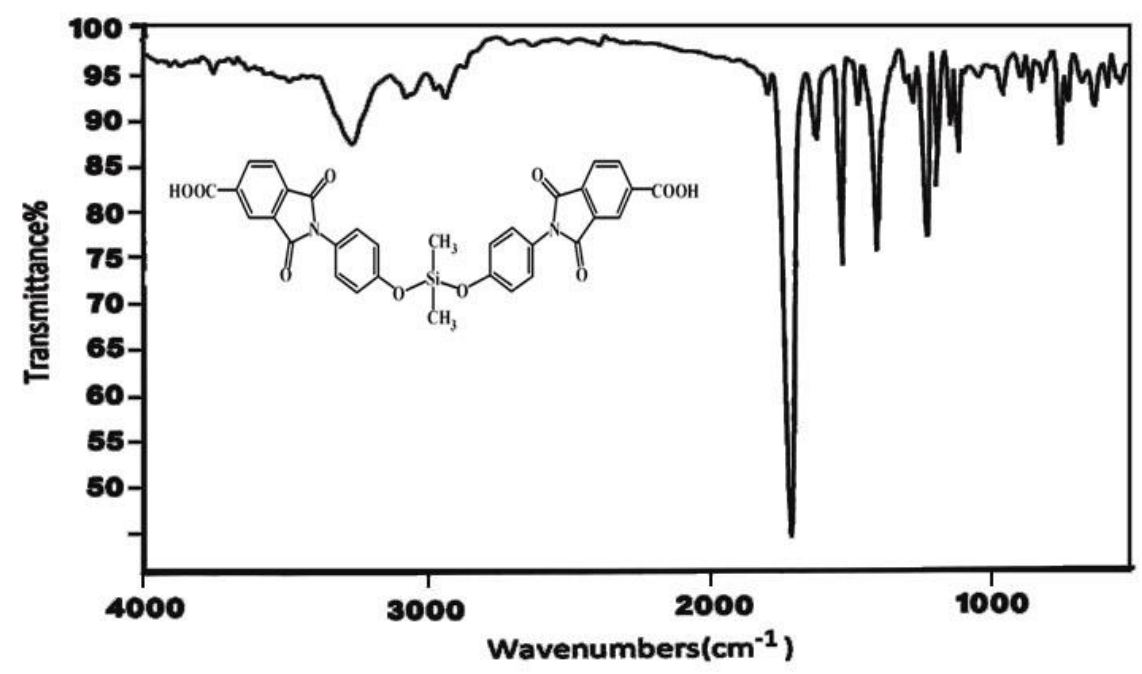

Fig. 1. FT-IR spectrum of $N, N^{\prime}$-bis-(4-trimellitimidophenoxy) dimethylsilane (5). 

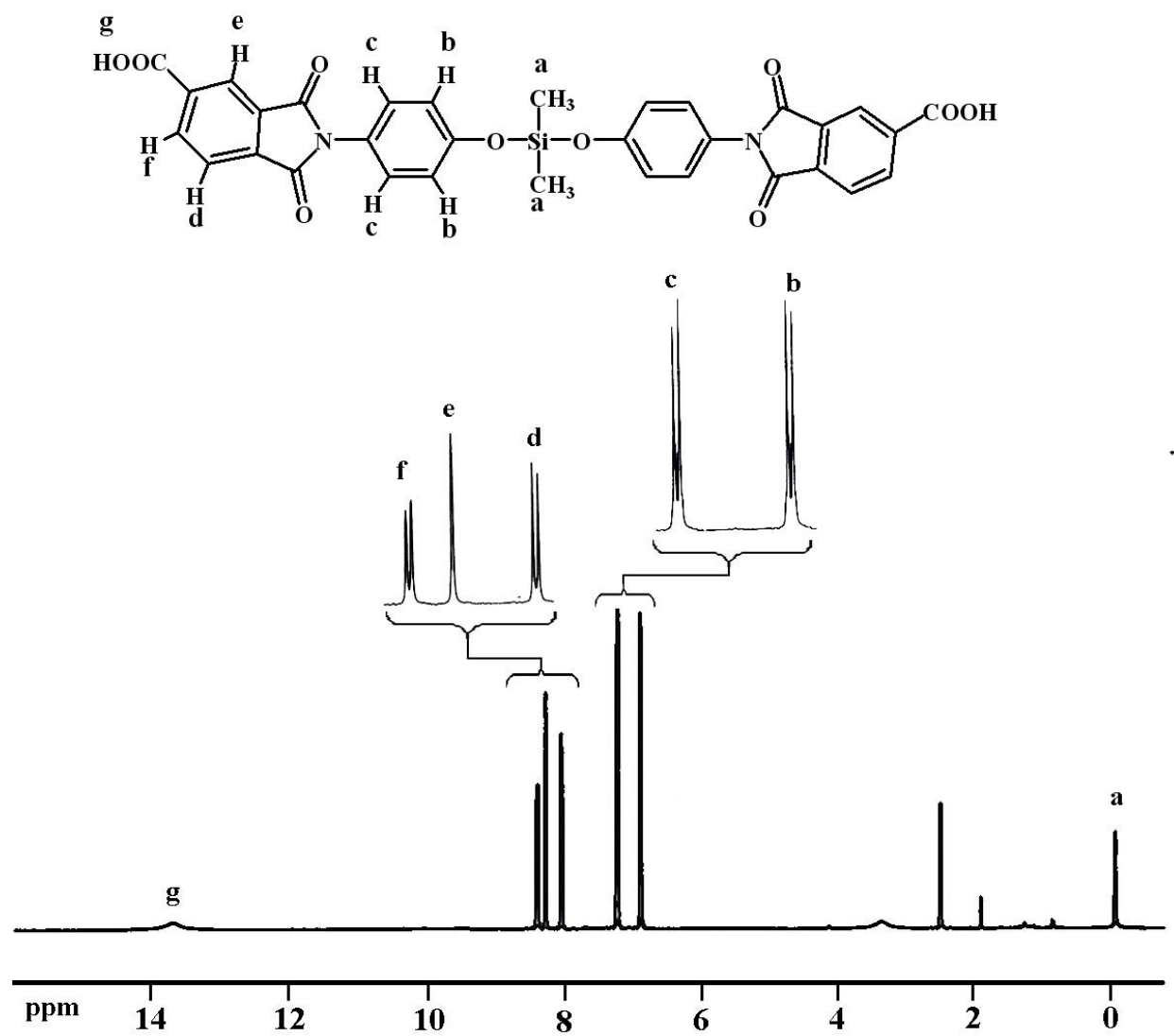

Fig. 2. ${ }^{1} \mathrm{H}-\mathrm{NMR} \quad(500 \mathrm{MHz})$ spectrum of $N, N^{\prime}$-bis-(4-trimellitimidophenoxy) dimethylsilane (5) in DMSO-d $\mathrm{d}_{6}$ at RT.
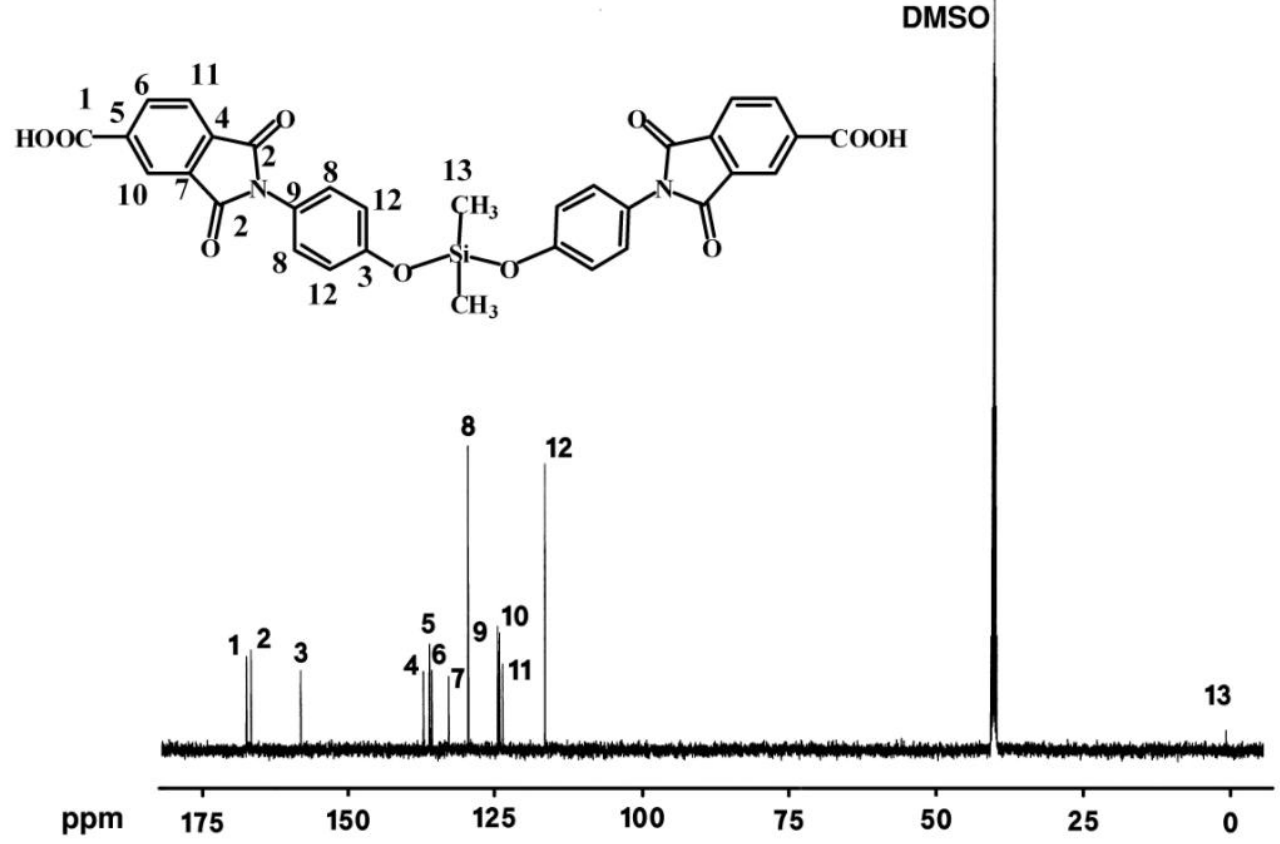

Fig. 3. ${ }^{13} \mathrm{C}-\mathrm{NMR} \quad(500 \mathrm{MHz})$ spectrum of $N, N^{\prime}$-bis-(4-trimellitimidophenoxy) dimethylsilane (5) in DMSO- $d_{6}$ at RT. 


\section{Polymer syntheses}

Direct polycondensation of a dicarboxylic acid with a diamine using TPP and Py as condensing agent to form amide bonds is an efficient way to obtain polyamides of moderate to high degree of polymerization on a laboratory scale. This method was successfully applied for the preparation of PAIS(7a-7h) from novel dicarboxylic acid $\mathbf{5}$ with various aromatic diamines (6a-6g) (Scheme 3). All of polymerization reactions in NMP in the presence of $\mathrm{CaCl}_{2}$ proceeded homogeneously.

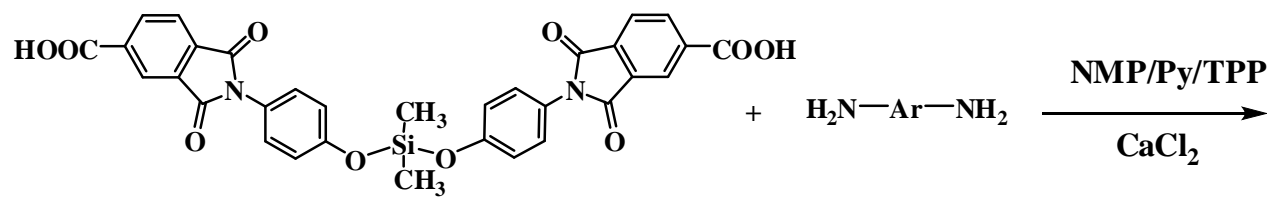

(5)

$(6 \mathbf{a}-6 h)$

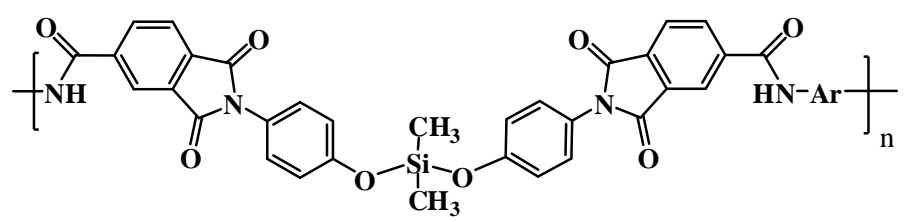

(PAIS 7a-7h)

6a, 7a: Ar=

6d, 7d: Ar=

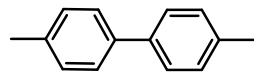

6b,7b: $A r=$

6c, 7c: $\mathrm{Ar}=$<smiles>Cc1ccc(Cc2ccc(C)cc2)cc1</smiles>

6e, 7e: Ar=<smiles>Cc1cccc2c(C)cccc12</smiles>

6f, 7f: $\mathrm{Ar}=$<smiles>Cc1ccc(C)c(C)c1</smiles>

6g, $7 \mathrm{~g}: \mathrm{Ar}=$

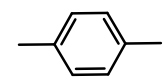

6h, 7h: Ar=<smiles>Cc1cccc(C)c1</smiles>

Scheme 3. Polymerization reactions of monomer 5 with aromatic diamines.

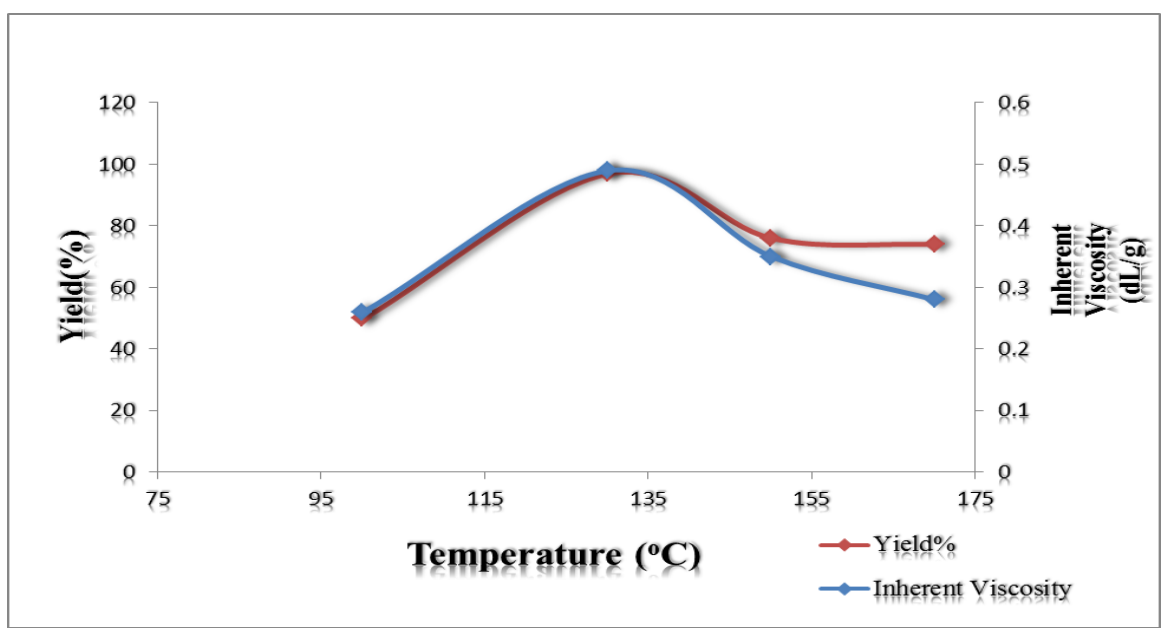

Fig. 4. The effect of reaction temperature on PAIS-7a yield and inherent viscosity (inherent viscosity were measured at concentration of $0.5 \mathrm{~g} / \mathrm{dL}$ in DMF, reaction conditions: $\mathrm{NMP} / \mathrm{Py}=2: 1, \mathrm{CaCl}_{2} / \mathrm{diacid}=2: 1$, reaction time $=6 \mathrm{~h}$ ). 


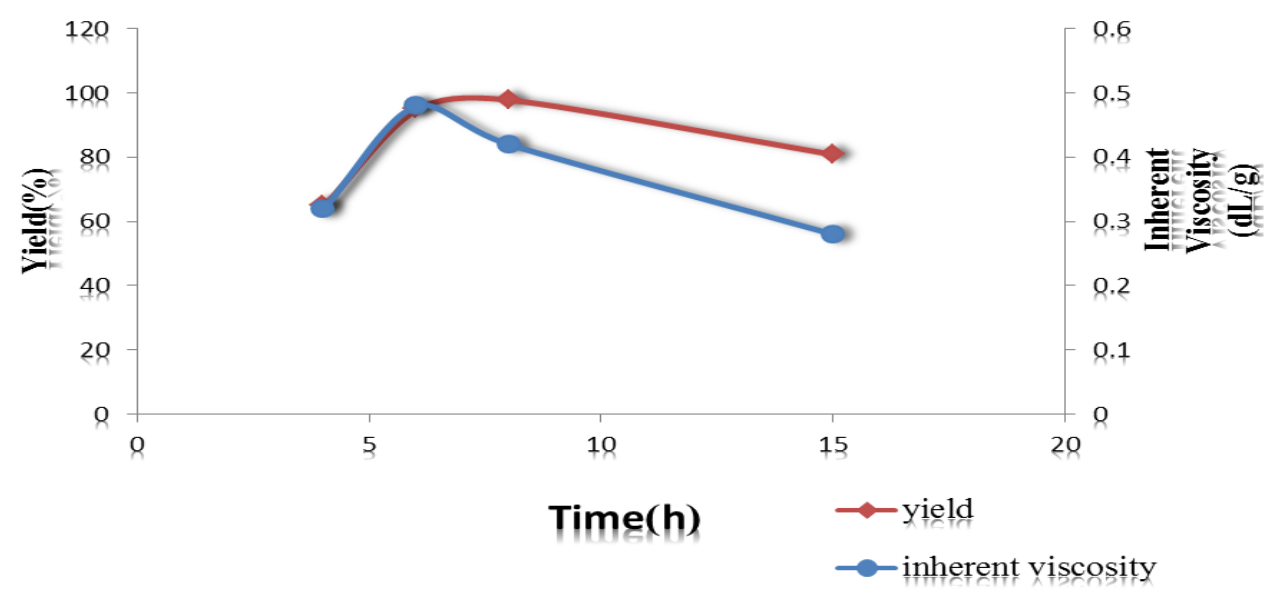

Fig. 5. The effect of reaction time on PAIS-7a yield and inherent viscosity (inherent viscosity were measured at concentration of $0.5 \mathrm{~g} / \mathrm{dL}$ in DMF, reaction conditions: $\mathrm{NMP} / \mathrm{Py}=2: 1, \mathrm{CaCl}_{2} /$ diacid $=2: 1$, reaction temperature $=130^{\circ} \mathrm{C}$ ).

Tab. 1. The optimum conditions for the preparation of PAISs using $\mathrm{TPP} / \mathrm{NMP} / \mathrm{Py} / \mathrm{CaCl}_{2}$ as a condensing agent.

\begin{tabular}{cc}
\hline Parameter & Optimum condition \\
\hline Reaction Temperature $\left({ }^{\circ} \mathrm{C}\right)$ & 130 \\
Reaction Time $(\mathrm{h})$ & 6 \\
$\mathrm{NMP} / \mathrm{Py}(\mathrm{mL}: \mathrm{mL})$ & $10: 3$ \\
$\mathrm{CaCl}_{2} /$ diacid $($ mole:mole) & $5: 1$ \\
\hline
\end{tabular}

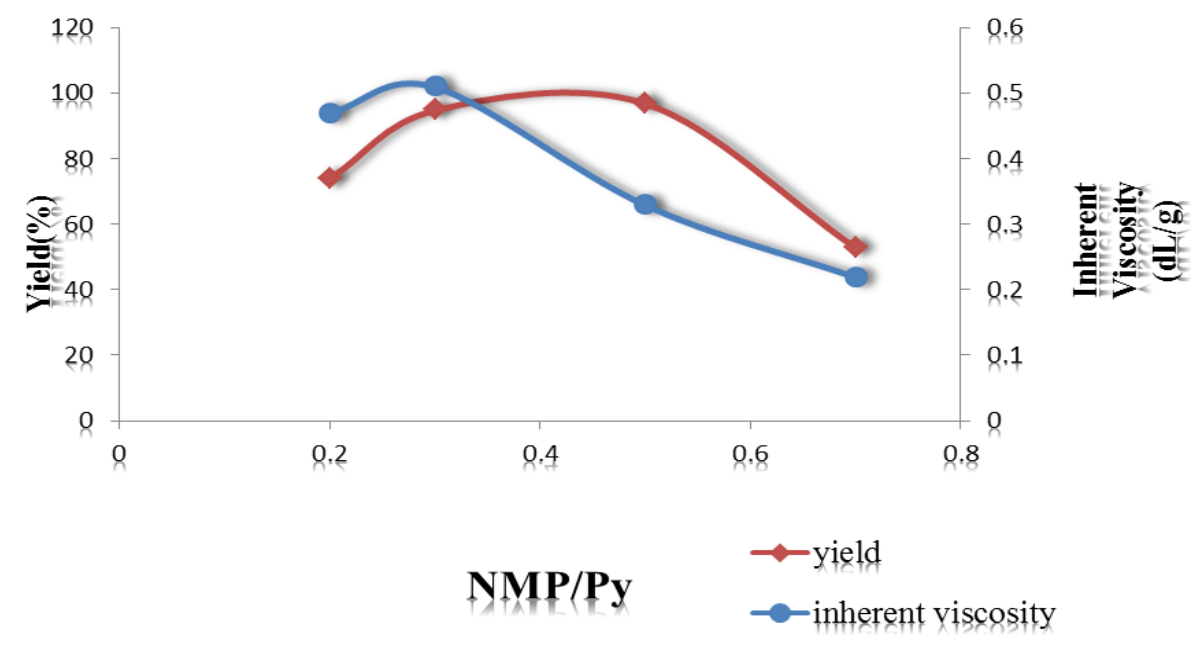

Fig. 6. The effect of NMP/Py ratio on PAIS-7a yield and inherent viscosity (inherent viscosity were measured at concentration of $0.5 \mathrm{~g} / \mathrm{dL}$ in DMF, reaction conditions: $\mathrm{CaCl}_{2} /$ diacid $=2: 1$, reaction time $=6 \mathrm{~h}$, reaction temperature $=130{ }^{\circ} \mathrm{C}$ ). 
Different parameters such as reaction time, reaction temperature, NMP/Py ratio and $\mathrm{CaCl}_{2} /$ diacid ratio have critical effect on polymerization reaction using phosphorylation reaction [32], so this parameters were modified with different reactions (Figures 4-7) and the best results were carefully chosen for direct polymerization reactions (Table 1). All of these parameters had acute effect on the polymer chain growth.

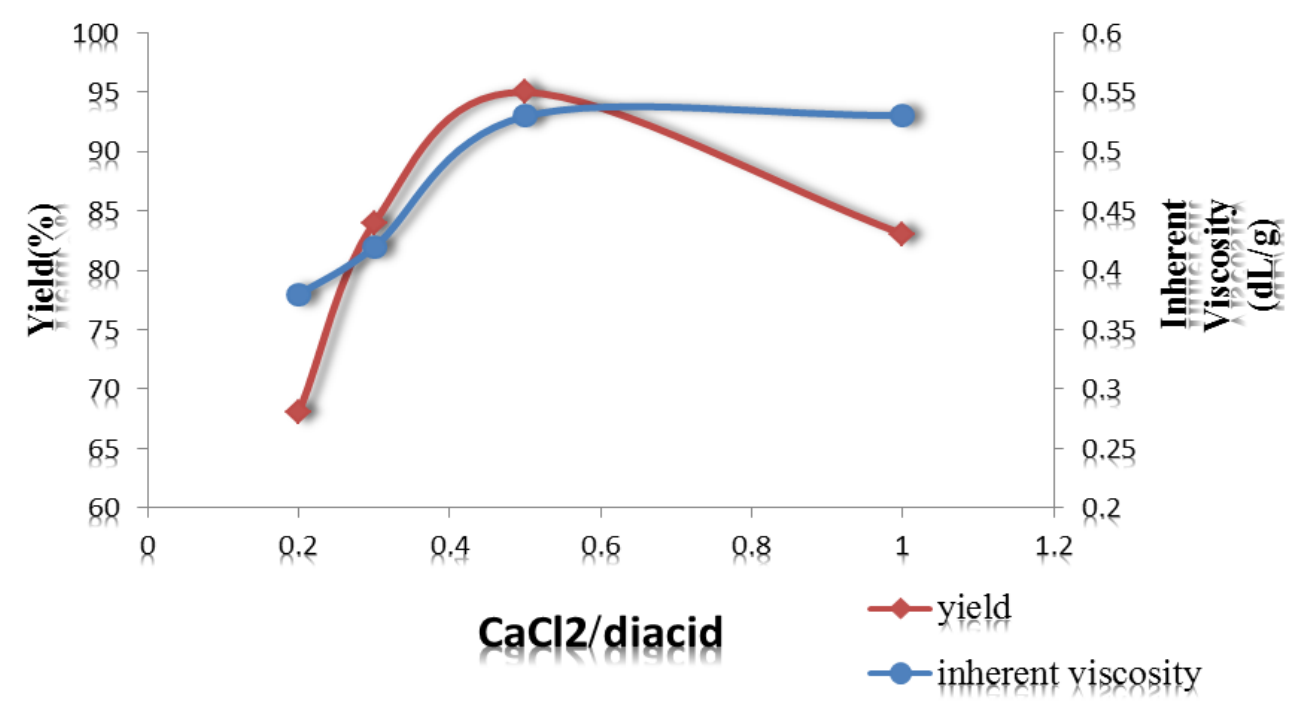

Fig. 7. The effect of $\mathrm{CaCl}_{2} /$ diacid ratio on PAIS-7a yield and inherent viscosity (inherent viscosity were measured at concentration of $0.5 \mathrm{~g} / \mathrm{dL}$ in DMF, reaction conditions: $\mathrm{NMP} / \mathrm{Py}=10: 3$, reaction time $=6 \mathrm{~h}$, reaction temperature $=130{ }^{\circ} \mathrm{C}$ ).

Tab. 2. Synthesis and some physical properties of PAIS(7a-7h) prepared using TPP/NMP/Py .

\begin{tabular}{|c|c|c|c|}
\hline Diamine & & Polymer & \\
\hline & Polymer code & $\eta_{\mathrm{inh}}(\mathrm{dL} / \mathrm{g})$ & Yield (\%) \\
\hline $6 a$ & PAIS-7a & $0.51^{b}$ & 97 \\
\hline $6 b$ & PAIS-7b & $0.35^{\mathrm{b}}$ & 98 \\
\hline $6 c$ & PAIS-7c & $0.31^{b}$ & 74 \\
\hline $6 d$ & PAIS-7d & $0.44^{b}$ & 87 \\
\hline $6 e$ & PAIS-7e & $0.24^{b}$ & 98 \\
\hline $6 f$ & PAIS-7f & $0.27^{b}$ & 94 \\
\hline $6 g$ & PAIS-7g & $0.27^{c}$ & 98 \\
\hline $6 \mathrm{~h}$ & PAIS-7h & $0.24^{\mathrm{b}}$ & 96 \\
\hline
\end{tabular}

The synthesis and some physical properties of these poly(amide-imide)s containing siloxane group in the main chain are listed in Table 2. The inherent viscosities of the 
resulting polymers under optimized conditions were in a range of $0.24-0.51 \mathrm{dL} / \mathrm{g}$ and the yields were $74-98 \%$.

\section{FT-IR study}

The structures of these polymers were confirmed as PAISs by means of FT-IR spectroscopy. The FT-IR spectra data of PAIS(7a-7h) are reported in Table 3 . The FT-IR spectra of all polymers showed absorptions around $3300-3400 \mathrm{~cm}^{-1}(\mathrm{~N}-\mathrm{H})$. Two absorptions (symmetry and asymmetry imide $\mathrm{C}=\mathrm{O}$ ) appeared around 1720, $1780 \mathrm{~cm}^{-1}$. Imide heterocyclic ring are confirmed using two other peaks approximately at $730,1385 \mathrm{~cm}^{-1}$. All of these PAISs exhibited absorption at 1649$1657 \mathrm{~cm}^{-1}$ that shows the presence of the amide groups in these polymers. $\mathrm{Si}-\mathrm{CH}_{3}$ peaks appeared in the region of $1250 \mathrm{~cm}^{-1}$. Other peak around $1100 \mathrm{~cm}^{-1}$ proves the existence of Si-O starching. The PAIS-7a showed characteristic absorptions at 1315, $1154 \mathrm{~cm}^{-1}$ due to $\mathrm{SO}_{2}$ group in polymer chain.

Tab. 3. FT-IR spectra of PAIS(7a-7h).

\begin{tabular}{|c|c|}
\hline Polymer code & Wavenumber $\left(\mathrm{cm}^{-1}\right)$ \\
\hline PAIS-7a & $\begin{array}{l}3336(\mathrm{~b}), 1784(\mathrm{w}), 1721(\mathrm{~s}), 1651(\mathrm{~m}), 1595(\mathrm{~m}), 1518(\mathrm{~s}), 1385(\mathrm{~m}), 1315(\mathrm{w}), \\
1238(\mathrm{sh}), 1154(\mathrm{w}), 1106(\mathrm{~m}), 1101(\mathrm{w}), 910(\mathrm{w}), 819(\mathrm{~m}), 735(\mathrm{~m}), 693(\mathrm{w}), \\
525(\mathrm{w}) .\end{array}$ \\
\hline PAIS-7b & $\begin{array}{l}3409(\mathrm{~b}), \quad 1787(\mathrm{w}), \quad 1727(\mathrm{~s}), \quad 1653(\mathrm{~m}), \quad 1513(\mathrm{~s}), \\
1099(\mathrm{~m}), 825(\mathrm{~m}), 732(\mathrm{w}) .\end{array}$ \\
\hline PAIS-7c & $\begin{array}{l}3320(\mathrm{~b}), 1774(\mathrm{w}), 1725(\mathrm{~s}), 1656(\mathrm{~m}), 1594(\mathrm{~m}), 1511(\mathrm{~s}), 1394(\mathrm{~m}), 1318(\mathrm{~m}), \\
1242(\mathrm{~m}), 1159(\mathrm{~m}), 1118(\mathrm{~m}), 1014(\mathrm{w}), 11(\mathrm{w}), 814(\mathrm{~m}), 730(\mathrm{~m}), 524(\mathrm{w}) .\end{array}$ \\
\hline PAIS-7d & $\begin{array}{l}3327(\mathrm{~b}), 1781(\mathrm{w}), 1718(\mathrm{~s}), 1649(\mathrm{~m}), 1587(\mathrm{~m}), 1511(\mathrm{~s}), 1387(\mathrm{~m}), 1332(\mathrm{w}), \\
1242(\mathrm{~m}), 1173(\mathrm{w}), 1125(\mathrm{sh}), 1001(\mathrm{w}), 821(\mathrm{~s}), 725(\mathrm{~m}), 662(\mathrm{w}), 524(\mathrm{w}) .\end{array}$ \\
\hline PAIS-7e & $\begin{array}{l}3253(\mathrm{~b}), 1786(\mathrm{w}), 1711(\mathrm{~s}), 1657(\mathrm{~s}), 1521(\mathrm{~s}), 1385(\mathrm{~m}), 1385(\mathrm{~m}), 1269(\mathrm{~m}), \\
1100(\mathrm{~s}), 780(\mathrm{w}), 721(\mathrm{sh}) .\end{array}$ \\
\hline PAIS-7f & $\begin{array}{l}3424(\mathrm{~b}), 1784(\mathrm{w}), 1719(\mathrm{~s}), 1658(\mathrm{~s}), 1517(\mathrm{~m}), 1393(\mathrm{~m}), 1250(\mathrm{~m}), 1126(\mathrm{sh}), \\
931(\mathrm{w}), 735(\mathrm{~m})\end{array}$ \\
\hline PAIS-7g & $\begin{array}{l}3320(\mathrm{~b}), 1785(\mathrm{w}), 1718(\mathrm{~s}), 1649(\mathrm{~m}), 1553(\mathrm{w}), 1511(\mathrm{~m}), 1394(\mathrm{~m}), 1235(\mathrm{~m}), \\
1118(\mathrm{~m}), 814(\mathrm{~m}), 732(\mathrm{~m}), 669(\mathrm{w}), 524(\mathrm{~m}) .\end{array}$ \\
\hline PAIS-7h & $\begin{array}{l}3442(\mathrm{~b}), \quad 1779(\mathrm{w}), 1721(\mathrm{~s}), \quad 1654(\mathrm{~m}), \quad 1522(\mathrm{~m}), \\
1170(\mathrm{~m}), 1168(\mathrm{~m}), 1106(\mathrm{~m}), 835(\mathrm{w}), 728(\mathrm{~m}) .\end{array}$ \\
\hline
\end{tabular}

${ }^{1} \mathrm{H}$ NMR Study and elemental analysis

Figure 8 shows the ${ }^{1} \mathrm{H}$ NMR (500 MHz) spectrum of PAIS-7a as a typical of PAISs. In the ${ }^{1} \mathrm{H}$ NMR spectrum of this polymer, appearance of the $\mathrm{N}-\mathrm{H}$ proton of amide groups around $10.8 \mathrm{ppm}$ indicate amide group in the polymer's chain. The absorption of aromatic protons appeared at a range of $6.6-8.3 \mathrm{ppm}$. The proton of $\mathrm{CH}_{3}$ appeared at around $0.0 \mathrm{ppm}$ as a singlet peak. 


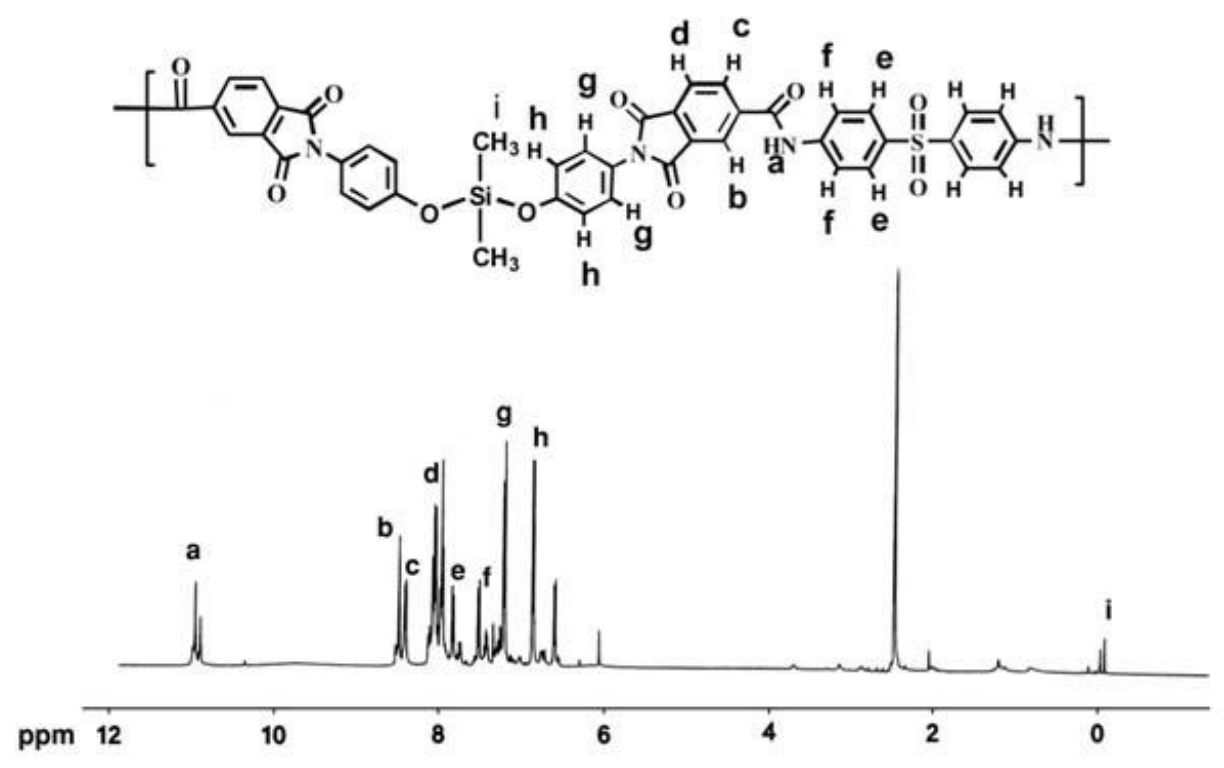

Fig. 8. ${ }^{1} \mathrm{H}-\mathrm{NMR}(500 \mathrm{MHz})$ Spectrum of PAIS-7a in DMSO- $\mathrm{d}_{6}$ at RT.

Elemental analysis data of PAISs are listed in Table 4. The chemical structures of these newly synthesized polymers were confirmed by the good agreement of the elemental analysis values with those of the calculated values.

Tab. 4. Elemental Analysis of typical PAISs.

\begin{tabular}{ccccccc}
\hline \multirow{2}{*}{$\begin{array}{c}\text { Polymer } \\
\text { code }\end{array}$} & Formula & & \multicolumn{4}{c}{ Elemental Analysis (\%) } \\
\cline { 4 - 7 } & & & $\mathrm{C}$ & $\mathrm{H}$ & $\mathrm{N}$ & $\mathrm{S}$ \\
\hline PAIS-7a & $\left(\mathrm{C}_{44} \mathrm{H}_{30} \mathrm{~N}_{4} \mathrm{O}_{10} \mathrm{SSi}\right)_{\mathrm{n}}$ & Calcd & 63.30 & 3.62 & 6.71 & 3.84 \\
& $(843.88)_{n}$ & Found & 62.86 & 3.98 & 6.51 & 3.64 \\
PAIS-7b & $\left(\mathrm{C}_{44} \mathrm{H}_{31} \mathrm{~N}_{4} \mathrm{O}_{9} \mathrm{Si}\right)_{n}$ & Calcd & 67.08 & 3.97 & 7.11 & 0.00 \\
& $(787.82)_{n}$ & Found & 65.92 & 4.21 & 6.89 & 0.15 \\
\hline
\end{tabular}

Solubility and Thermal properties

Because of flexible siloxane group in polymer's main chains these polymers are expected to have good solubility. The solubility of PAISs was tested quantitatively in various solvents. All of the PAISs are soluble in organic polar aprotic solvents such as DMF, DMAc, NMP and polar protic solvent such as $\mathrm{H}_{2} \mathrm{SO}_{4}$ at room temperature. The solubility of the polymers in other solvents such as methanol, ethanol, chloroform, dicholoromethane and ethylacetate are varied and depends on the structure of diamines segment in polymer chain, although these polymers are partial; soluble in these solvents (Table 5).

The thermal properties of PAIS-7a, PAIS-7c, PAIS-7d and PAIS-7g were evaluated by means of TGA/DTG in a nitrogen atmosphere at a heating rate of $10{ }^{\circ} \mathrm{C} / \mathrm{min}$. The temperature of $5 \%$ and $10 \%$ weight loss together with char yield at $600{ }^{\circ} \mathrm{C}$ have been 
calculated by means of thermograms (Table 6 ). The Figures $9-12$ shows the TGA thermograms of these polymers respectively.

Tab. 5. The solubility test result of PAISs ${ }^{a}$.

\begin{tabular}{cccccccccc}
\hline Polymer & NMP & DMAc & DMF & $\mathrm{H}_{2} \mathrm{SO}_{4}$ & $\mathrm{EtOAc}$ & $\mathrm{CH}_{3} \mathrm{OH}$ & $\mathrm{CH}_{3} \mathrm{CH}_{2} \mathrm{OH}$ & $\mathrm{CH}_{2} \mathrm{Cl}_{2}$ & $\mathrm{CHCl}_{3}$ \\
\hline PAIS-7a & ++ & ++ & ++ & ++ & +- & +- & +- & +- & +- \\
PAIS-7b & ++ & ++ & ++ & ++ & +- & - & - & +- & +- \\
PAIS-7c & ++ & ++ & ++ & ++ & + & + & + & + & + \\
PAIS-7d & ++ & ++ & ++ & ++ & - & +- & +- & - & - \\
PAIS-7e & ++ & ++ & ++ & ++ & - & +- & +- & - & - \\
PAIS-7f & ++ & ++ & ++ & ++ & + & + & + & + & + \\
PAIS-7g & ++ & ++ & ++ & ++ & - & +- & - & - & - \\
PAIS-7h & ++ & ++ & ++ & ++ & + & + & + & + & + \\
\hline
\end{tabular}

${ }^{a}$ Soluble at room temperature: ++ , Soluble at boiling point of solvent: + , Partial soluble: +- , Insoluble: -

These novel polymers are stable up to around $450{ }^{\circ} \mathrm{C}$ and show excellent thermal stability. The thermoanalysis data of these polymers are summarized in Table 6 . The TGA measurement of the polymers revealed that these new polymers exhibited good thermal stability, especially in term of char yields, in compare with other poly(amideimide)s contains analogous diacid without siloxane group [33].

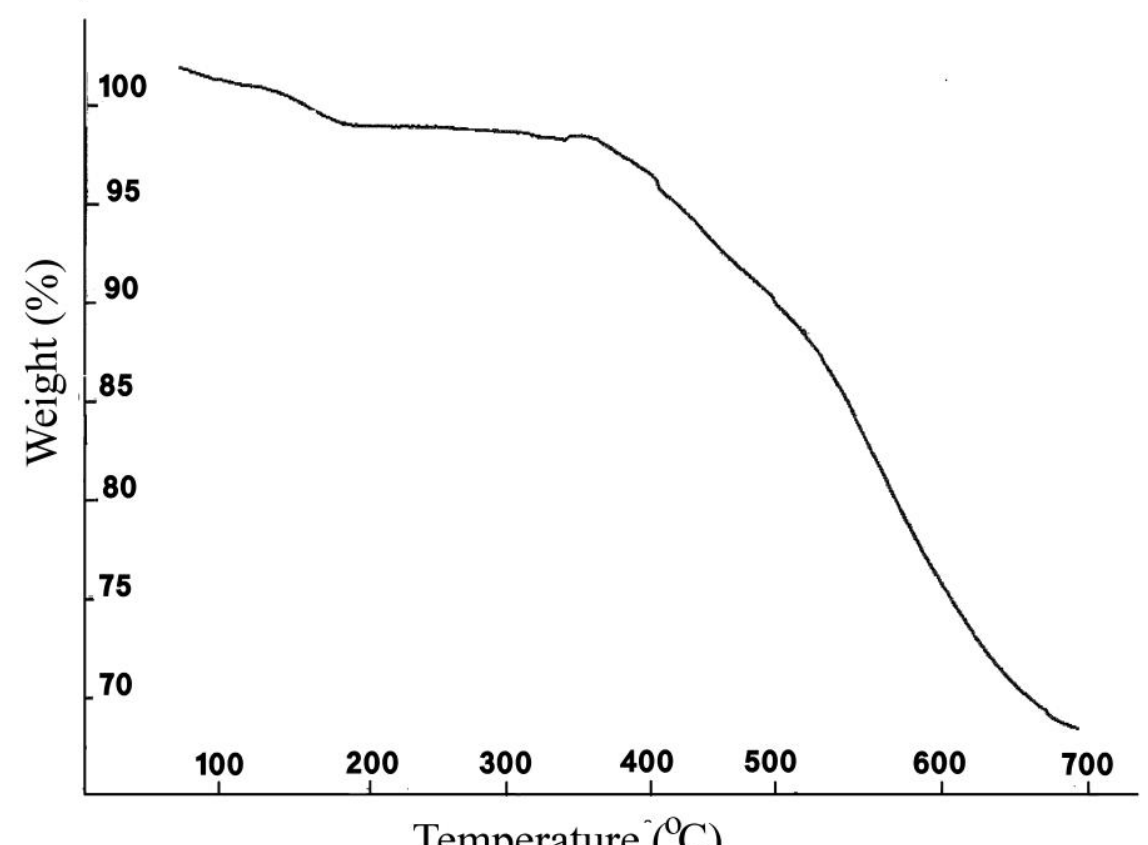

Temperature $\left({ }^{\circ} \mathrm{C}\right)$

Fig. 9. TGA thermograms of PAIS-7a under $\mathrm{N}_{2}$ atmosphere and a heating rate of 10 ${ }^{\circ} \mathrm{C} / \mathrm{min}$. 


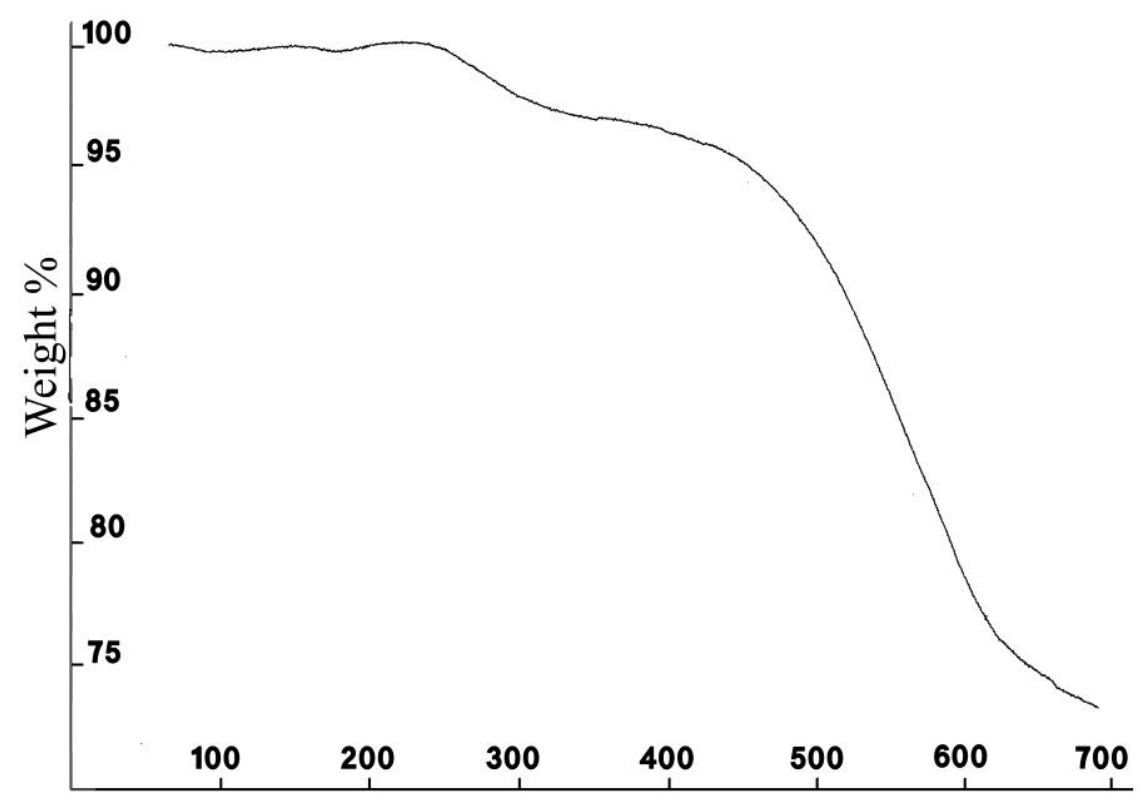

Temperature $\left({ }^{\circ} \mathrm{C}\right)$

Fig. 10. TGA thermograms of PAIS-7c under $\mathrm{N}_{2}$ atmosphere and a heating rate of 10 ${ }^{\circ} \mathrm{C} / \mathrm{min}$.

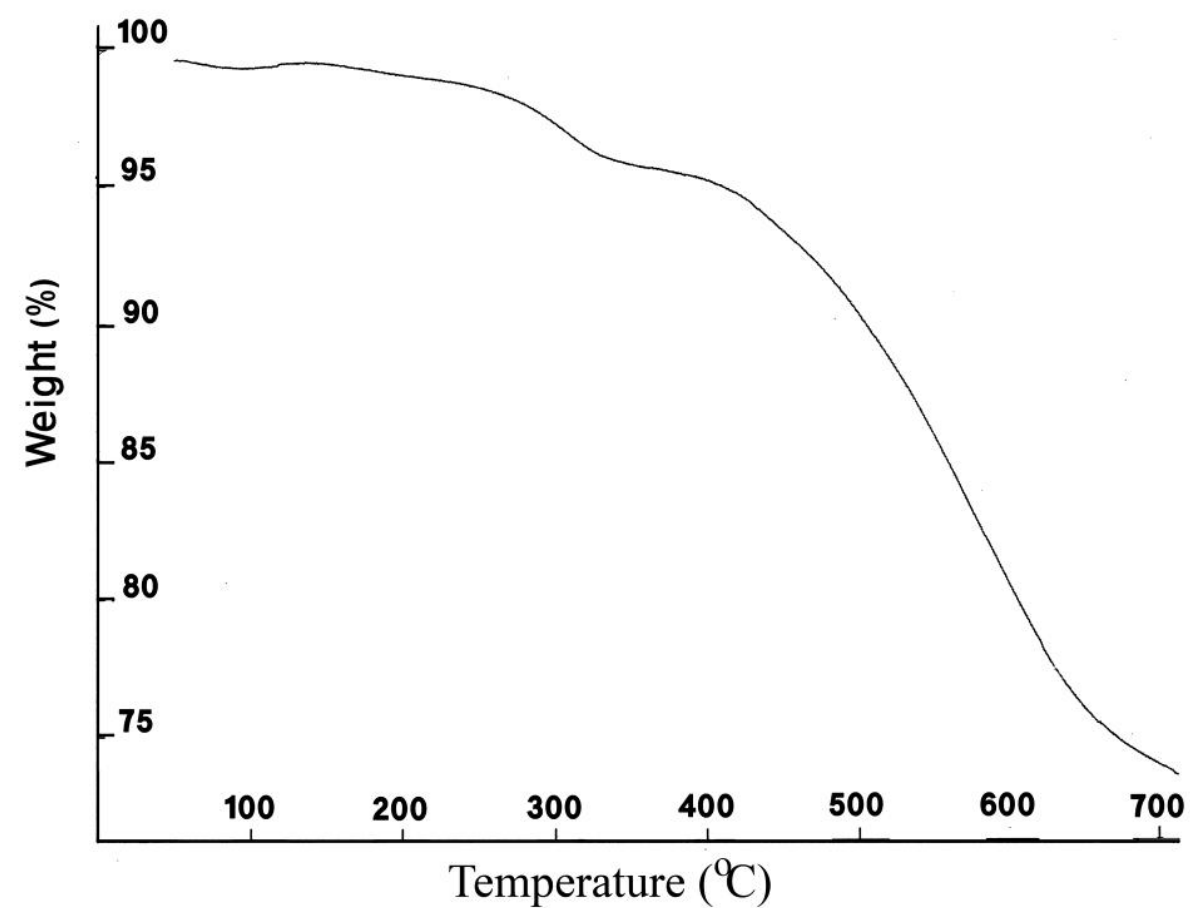

Fig. 11. TGA thermograms of PAIS-7d under $\mathrm{N}_{2}$ atmosphere and a heating rate of 10 ${ }^{\circ} \mathrm{C} / \mathrm{min}$.

DSC spectra of PAIS-7a, PAIS-7c, PAIS-7d and PAIS-7g show that $T_{g}$ of these polymers are in a range of $170-290{ }^{\circ} \mathrm{C}$ (Table 6). So in spite of high thermal stability of these new class polymers, they can be processable. The reason of this observation is attributed to the existence softening of siloxane moieties in the polymers main chains. 


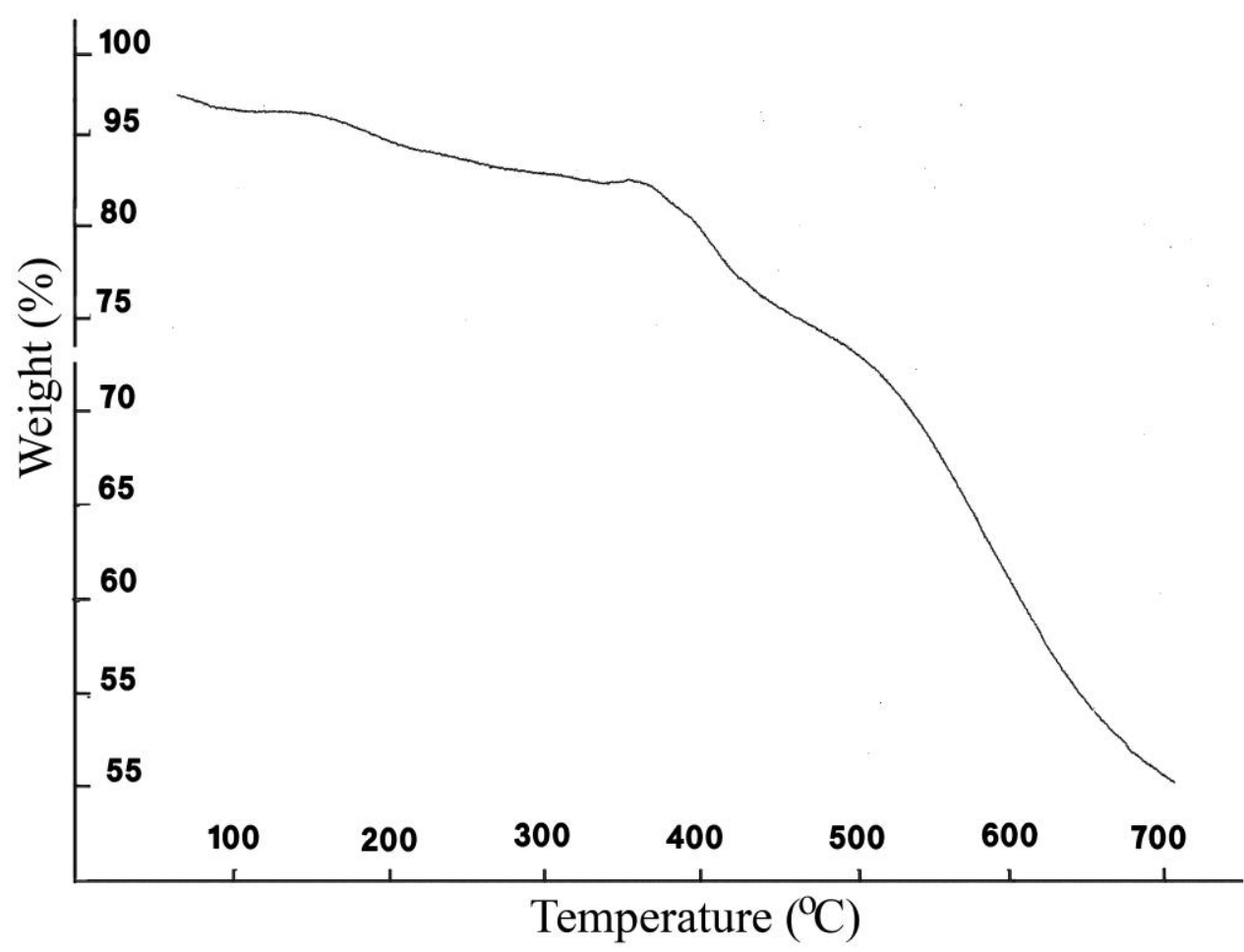

Fig. 12. TGA thermograms of PAIS-7g under $\mathrm{N}_{2}$ atmosphere and a heating rate of 10 ${ }^{\circ} \mathrm{C} / \mathrm{min}$.

Tab. 6. Thermal behavior of some PAISs prepared using TPP/NMP/Py as a condensing agent.

\begin{tabular}{ccccc}
\hline Polymer Code & $\mathrm{T}_{5}{ }^{\mathrm{a}}\left({ }^{\circ} \mathrm{C}\right)$ & $\mathrm{T}_{10}{ }^{\mathrm{b}}\left({ }^{\circ} \mathrm{C}\right)$ & Char Yield $(\%)^{\mathrm{C}}$ & $\mathrm{T}_{g}\left({ }^{\circ} \mathrm{C}\right)$ \\
\hline PAIS-7a & 420 & 495 & 76 & 190 \\
PAIS-7c & 460 & 525 & 81 & 255 \\
PAIS-7d & 445 & 525 & 82 & 290 \\
PAIS-7g & 335 & 435 & 76 & 175 \\
\hline $\begin{array}{l}\text { a Temperature at which } \\
\text { atmosphere. } \\
\text { b }\end{array}$ & Temperature at which & $10 \%$ weight loss was recorded by TGA at heating rate of $10{ }^{\circ} \mathrm{C} /$ min under $\mathrm{N}_{2}$ \\
atmosphere. \\
c Weight percent of the material left undecomposed after TGA at maximum temperature $600{ }^{\circ} \mathrm{C}$ in a $\mathrm{N}_{2}$ \\
atmosphere.
\end{tabular}

\section{Conclusions}

In this study we have successfully synthesized a novel aromatic dicarboxylic acid (5), containing siloxane group. A series of novel aromatic PAISs were prepared by the direct polycondensation from the compound $\mathbf{5}$ with various aromatic diamines using TPP/NMP/Py as a condensing agent in the presence of $\mathrm{CaCl}_{2}$. The main advantages of this polycondensation reaction are that in this procedure we do not need to prepare diacid chloride, therefore saves time and energy. The resulting polymers were obtained in high yields and inherent viscosities. 
The results presented herein demonstrate clearly that incorporating of imide heterocyclic rings into the polymer chain as well as combination of wholly aromatic backbone, together with existence of polarizable dimethyl siloxane group (in compare with carbon analogous) in the presence of amide functional groups remarkably enhanced the thermal stability of the new polymers.

Flexible siloxane groups in the main chain of PAISs polymers disturbed the strong interchain forces and inherent macromolecular rigidity and cause these novel polymers to be soluble in most polar organic solvents. These polymers show moderate $T_{g}$. This property together with high solubility of these polymers makes these polymers processable.

From the chemical point of view the siloxane group imparts the polymer's main chain increased sensibility to hydrolysis that can cause chain breaking. So these polymers are expected to be biodegradable and therefore are classified under environmentally friendly polymers.

\section{Experimental}

\section{Materials}

All chemicals were purchased from Fluka Chemical Co. (Buchs, Switzerland), Aldrich Chemical Co. (Milwaukee, WI), Riedel-deHaen AG (Seelze, Germany) and Merck Chemical Co. p-Aminophenol (1) (from Merck), dichlorodimethylsilane (2) (from Aldrich), and triphenyl phosphite (from Riedel de Haen) were used as received. 4,4'Diaminodiphenylsulfone (6a) was used as obtained without further purification. Benzidine (6d) and 4,4'-diaminodiphenyl methane (6c) was purified by recrystallization from ethanol and water, respectively. 4,4'- Diaminodiphenylether (6b), p-phenylenediamine (6g), $m$-phenylenediamine (6h) and 2,5-diaminotoluene (6f) were purified by sublimation.

\section{Techniques}

Proton nuclear magnetic resonance $\left({ }^{1} \mathrm{H}-\mathrm{NMR}, 500 \mathrm{MHz}\right)$ spectra were recorded in DMSO- $d_{6}$ solution using a Bruker (Germany) Avance 500 instrument at Sharif University of Technology, Tehran, Iran. FT-IR spectra were recorded on Nicolet Impact 400 spectrophotometer. The spectra of solids were obtained using $\mathrm{KBr}$ pellets. The vibrational transition frequencies are reported in wave numbers $\left(\mathrm{cm}^{-1}\right)$. Band intensities are assigned as weak (w), medium (m), shoulder (sh), strong (s) and broad (br). Inherent viscosities were measured by using a Cannon-Fenske Routine Viscometer (Germany) at concentration of $0.5 \mathrm{~g} / \mathrm{dL}$ at $25{ }^{\circ} \mathrm{C}$. Thermal gravimetric analysis (TGA) data for polymers were taken on Perkin Elmer in nitrogen atmosphere at a rate of $10^{\circ} \mathrm{C} / \mathrm{min}$. Elemental analyses were performed by the Iran Polymer and Petrochemical Research Institute, Tehran, Iran.

\section{Synthesis of bis-(p-aminophenoxy) dimethylsilane (3)}

Bis-( $p$-aminophenoxy) dimethylsilane (3) was prepared by some modification of reported procedure [29].

A mixture of $p$-aminophenol (1) $(2.18 \mathrm{~g}, 0.02 \mathrm{~mol})$, anhydrous triethylamine $(3 \mathrm{~mL})$, and $40 \mathrm{~mL}$ toluene in a $100 \mathrm{~mL}$ three-necked flask was stirred with magnetic stirrer for $1 \mathrm{~h}$ at room temperature. The reaction was cooled with an ice bath and purged with nitrogen atmosphere, and then dichlorodimethylsilane $(2)(1.2 \mathrm{~mL}, 0.01 \mathrm{~mol})$ was 
added dropwise. This mixture was stirred for $3 \mathrm{~h}$ in ice bath and for $24 \mathrm{~h}$ in gentle reflux condition. After cooling the reaction mixture was filtered and solvent was removed. The crude product was then dissolved in chloroform and filtered. The solvent of the filtrate was removed and the residue was finally dried in vacuum at 50 ${ }^{\circ} \mathrm{C}$. The final product was viscous brown oil. Yield $=2.24 \mathrm{~g}, 81 \%$.

FT-IR: 3400(br), 2950(s), 1730(s), 1620(w), 1510(s), 1460(m), 1390(w), 1260(s), 1125(m), 1077(s), 933(s), 809(s), 768(s), 535(w).

\section{Synthesis of N,N'-bis-(4-trimellitimidophenoxy) dimethylsilane (5)}

In a round bottom flask equipped with a condenser and magnetic stirrer, $\operatorname{bis}(p$ aminophenoxy)dimethyl silane (3) $(2.47 \mathrm{~g}, 10 \mathrm{mmol})$ and trimellitic anhydride (4) $(3.84 \mathrm{~g}, 20 \mathrm{mmol})$ were suspended in glacial acetic acid $(50 \mathrm{~mL})$ and refluxed for 15 $\mathrm{h}$. The solvent was removed under reduced pressure and the residue was poured in $50 \mathrm{~mL}$ of a cold mixture of water and $5 \mathrm{~mL}$ concentrated hydrochloric acid. The white precipitate was formed, filtered off and dried under vacuum to give $5.72 \mathrm{~g}$ (yield 92\%) of diacid 5.

FT-IR (KBr): 2500-3500 (br), 1782 (w), 1705 (s), 1608 (m), 1510 (s), $1454(\mathrm{~m}), 1390$ (s), 1211 (s.sh), $1176(\mathrm{~m}), 1092(\mathrm{~s}, \mathrm{sh}), 1016(\mathrm{w}), 932(\mathrm{~m}), 828$ (m,sh), $723(\mathrm{~m}, \mathrm{sh})$, $654(\mathrm{w}), 598(\mathrm{w}) \mathrm{cm}^{-1}$.

${ }^{1} \mathrm{H}$ NMR $\left(500 \mathrm{MHz}\right.$, DMSO- $\left.d_{6}\right): \delta=0.0(\mathrm{~S}, 3 \mathrm{H}), 6.8(\mathrm{~d}, 2 \mathrm{H}), 7.2(\mathrm{~d}, 2 \mathrm{H}), 8(\mathrm{~d}, 1 \mathrm{H}), 8.2$ $(\mathrm{s}, 1 \mathrm{H}), 8.3(\mathrm{~d}, 1 \mathrm{H}) .13 .8(\mathrm{~s}, 1 \mathrm{H}) \mathrm{ppm}$.

${ }^{13} \mathrm{C}$ NMR $\left(500 \mathrm{MHz}\right.$, DMSO- $\left.d_{6}\right): \delta=1,116.3,123.5,124.1,124.4,129.5,132.9$, $135.7,136.2,137.2,158.2,166.7,167.4,167.5 \mathrm{ppm}$.

Elemental analysis: $\left(\mathrm{C}_{32} \mathrm{H}_{22} \mathrm{~N}_{2} \mathrm{O}_{10} \mathrm{Si}\right)$ (622.61): calcd. $\mathrm{C}=61.73 \%, \mathrm{H}=3.56 \%, \mathrm{~N}=$ $4.50 \%$; Found: $\mathrm{C}=61.28 \%, \mathrm{H}=3.65 \%, \mathrm{~N}=4.42 \%$.

\section{Polymer syntheses}

Polymerization reactions were carried out using triphenyl phosphite (TPP) and pyridine (Py) as a condensing agent in the presence of calcium chloride and $\mathrm{N}$ methyl-2-pyrrolidone (NMP) as a solvent. Different parameters such as reaction time, reaction temperature, NMP/Py ratio and amount of $\mathrm{CaCl}_{2}$ have influence on polymers yield and inherent viscosities. In a typical procedure for preparation of PAIS-7a, a mixture of $0.2000 \mathrm{~g}\left(3 \times 10^{-4} \mathrm{~mol}\right)$ of dicarboxylic acid $5,0.0744 \mathrm{~g}\left(3 \times 10^{-4} \mathrm{~mol}\right)$ of diamine $6 \mathrm{a}, 0.14 \mathrm{~mL}$ of TPP, $0.14 \mathrm{~mL}$ of pyridine, $0.0714 \mathrm{~g}$ of calcium chloride and $0.46 \mathrm{~mL}$ of NMP was heated at $130{ }^{\circ} \mathrm{C}$ for $6 \mathrm{~h}$. After cooling, the viscous reaction mixture was poured into $30 \mathrm{~mL}$ of methanol with constant stirring. The precipitate was collected on a filter and washed thoroughly with methanol and water. The solid was dried under vacuum to give $0.2714 \mathrm{~g}$ of PAIS-7a (97\% yield). The inherent viscosity of the resulting polyamide measured at a concentration of $0.5 \mathrm{~g} / \mathrm{dL}$ at $25{ }^{\circ} \mathrm{C}$ in DMF was $0.51 \mathrm{dLg}^{-1}$,

FT-IR (KBr): 3336 (b), 1784 (w), 1721 (s), 1651 (m), $1595(\mathrm{~m}), 1518$ (s), $1385(\mathrm{~m})$, $1315(\mathrm{w}), 1238(\mathrm{sh}), 1154(\mathrm{w}), 1106(\mathrm{~m}), 101(\mathrm{w}), 910(\mathrm{w}), 819(\mathrm{~m}), 735(\mathrm{~m}), 693(\mathrm{w})$, $525(w) \mathrm{cm}^{-1}$.

All of the polymers were prepared using a similar procedure. 


\section{Acknowledgements}

Support from Islamic Azad University, Shahreza Branch (IAUSH) Research Council is gratefully acknowledged.

\section{References}

[1] Ghosh, M. K.; Mittal, K. L. Polyimides: Fundamentals and Applications. New York, Marcel Dekker, 1996, p 309.

[2] Wilson, D.; Stenzenberger, H. D.; Hergenrother, P. M. Polyimides. New York, Chapman \& Hall, 1990, p 227.

[3] Ayala, V.; Maya, M.; Garcia, J. M.; de la Campa, J. G.; Lozano, A. E.; de Abajo, J. J. Polym. Sci., Part A: Polym. Chem. 2005, 43, 112.

[4] Mallakpour, S.; Kolahdoozan, M. Polymer J. 2008, 40, 513.

[5] Mallakpour, S.; Kolahdoozan, M. J. Appl. Polym. Sci. 2007, 104, 1248.

[6] Mallakpour, S.; Kolahdoozan, M. e-Polymers 2006, no. 020.

[7] Liaw, D. J.; Liaw, B. Y. Polymer 2001, 42, 839.

[8] Nakata, S.; Brisson, J. J. J. Polym. Sci., Part B: Polym. Physics. 1997, 35, 2379.

[9] Liaw, D. J.; Fan, C. L.; Lin, C. C.; Wang, K.L. J. Appl. Polym. Sci. 2004, 92, 2486.

[10] Mehdipour-Ataei, S. Eur. Polym. J. 2005, 41, 65.

[11] Mallakpour, S.; Kolahdoozan, M. Iran. Polym. J. 2006, 15, 307.

[12] Liou, G. S.; Hsiao, S. H. J. Polym. Sci., Part A: Polym. Chem. 2001, 39, 1786.

[13] Behniafar, H.; Jafari, A.; J. Appl. Polym. Sci. 2006, 100, 3203.

[14] Ferrero, E.; Espeso, J. F.; de la Campa, J. G.; de Abajo, J.; Lozano, A. E. J. Polym. Sci., Part A: Polym. Chem. 2002, 40, 3711.

[15] Hsiao, C. H.; Yang, C. P.; Chen, C. W.; Liou, G. S. Eur. Polym. J. 2005, 41, 511.

[16] Sava, I.; Bruma, M. Macromol. Symp. J. 2006, 239, 36.

[17] Toiserkani, H.; Sheibani, H.; Saidi, K. Eur. Polym. J. 2010, 46, 185.

[18] Ferrero, E.; Espeso, J. F.; de la Campa, J. G.; Abajo, J. D.; Lozano, A. E. J. Polym. Sci., Part A: Polym. Chem. 2002, 40, 3711.

[19] Mallakpour, S.; Kolahdoozan, M. React. Funct. Polym. 2008, 68, 91.

[20] Liaw, D. J.; Hsu, P. N.; Chen, W. H.; Lin, S. L. Macromolecules 2002, 35, 4669.

[21] Ojha, U. P.; Kumar, A. D. J. Polym. Sci., Part A: Polym. Chem. 2006, 44, 3479.

[22] Sava, I.; Schulz, B.; Zhu, S.; Bruma, M. High. Perf. Polym. 1995, 7, 493.

[23] Sava, I.; Szesztay, M.; Bruma, M.; Mercer, F.; Schulz, B. Die Angew. Makromol. Chem. 1997, 253, 169.

[24] Corriu, R. J. P. Angew. Chem. Int. Ed. 2000, 39, 1376.

[25] Kwon, S.; Lee, K.; Bae, W.; Kima, H. J. Supercritical Fluids 2008, 45, 391.

[26] Mashak, A.; Rahimi, A. Iran. Polym. J. 2009, 18, 279.

[27] Hamciuc, E.; Bruma, M.; Kopnick, T.; Kaminorz, Y.; Schulz, B. Polymer 2001, $42,1809$.

[28] Zhang, B.; Wang, Z.; Wang, Z.; Li, J.; Leng, S.; Shen, C.; Jiang, Y. Polymer 2009, 50, 2025.

[29] Liaw, D. J.; Yang, W. C. O.; Li, L. J.; Yang, M. H. J. Appl. Polym. Sci. 1997, 63, 369.

[30] Liaw, D. J.; Ou, D. L. J. Appl. Polym. Sci. 1996, 62, 9.

[31] Wang, F.; Kaafarani, B. R.; Neckers, D. C. Macromolecules 2003, 36, 8225.

[32] Yamazaki, N.; Yamazaki, M.; Matsumoto, M.; Higashi, F. J. Polym. Sci., Polym Chem. Ed. 1975, 13, 1373.

[33] Faghihi, K.; Hajibeygi, M. J. Appl. Polym. Sci. 2004, 92, 3447. 